\title{
Fiber Orientation Factor on Rectangular Cross-Section in Concrete Members
}

\author{
Seong-Cheol Lee, Jeong-Hwan Oh, and Jae-Yeol Cho
}

\begin{abstract}
In order to predict the post-cracking tensile behavior of fiber reinforced concrete, it is necessary to evaluate the fiber orientation factor which indicates the number of fibers bridging a crack. For investigation of fiber orientation factor on a rectangular section, in this paper, dog-bone fiber reinforced concrete specimens were prepared with the variables of concrete compressive strength, rectangular cross-section size, fiber type, and fiber volumetric ratio. After direct tension tests, the fiber orientation factor could be evaluated through counting the number of fibers on a crack. From the test results, it was investigated that the fiber orientation factor was larger than 0.5 which is generally adopted for large members, as fibers distribution is affected by the specimen size. For rational prediction of the fiber orientation factor on a rectangular concrete section, a simple model was derived from the Diverse Embedment Model (DEM), which is a rigorous model to predict the tensile behavior of steel fiber reinforced concrete. From the comparison of the measured data and the predicted values, it was found that the actual fiber orientation factor was well predicted by the proposed model.
\end{abstract}

Index Terms-Fiber orientation factor, fiber reinforced concrete, rectangular cross-section, steel fiber.

\section{INTRODUCTION}

For last a couple of decades, a number of researches [1]-[4] have been conducted to use steel fiber reinforced concrete as a structural member since steel fiber reinforced concrete exhibits ductile tensile behavior even after cracking. Meanwhile, several models [5]-[11] have been proposed in order to quantitatively represent the ductile tensile behavior of steel fiber reinforced concrete. From the models for the tensile behavior of steel fiber reinforced concrete, the tensile stress attained by steel fibers bridging a crack is generally evaluated by the followings;

$$
f_{f}=\alpha_{f} V_{f} \sigma_{f, a v g}
$$

where, $f_{f}$ is tensile stress attained by steel fibers, $\alpha_{f}$ is fiber orientation factor, $V_{f}$ is fiber volumetric ratio, and $\sigma_{f, a v g}$ is average tensile stress of fibers at a crack.

As presented in the equation, the tensile stress of steel fiber reinforced concrete is directly affected by the fiber orientation factor. Generally, the fiber orientation factor is

Manuscript received May 10, 2014; revised July 20, 2014.

S. C. Lee is with KEPCO Nuclear Graduate School, Ulsan, South Korea (e-mail: sclee@kings.ac.kr).

J. H. Oh is with the Office of Offshore Windpower Promotion, KETEP, and Seoul in South Korea (e-mail: ffjung45@gmail.com).

J. Y. Cho is with the Dept. of Civil and Environmental Engineering, Seoul National University, Seoul, South Korea (e-mail: jycho@snu.ac.kr).
0.5 , which is theoretically derived for randomly distributed fibers in large concrete members. However, the fiber orientation factor can be significantly affected by the concrete member size; it reaches up to 1.0 when the concrete cross-section is the same with the cross-section of a fiber. Since experimental programs with steel fiber reinforced concrete are generally conducted with relatively small specimens in a laboratory, it is important to more rationally evaluate the fiber orientation factor with the consideration of concrete member size as well as fiber length.

In this paper, therefore, the fiber orientation factor in small concrete members will be experimentally evaluated, and a simple model will be derived for the fiber orientation factor considering concrete member size and fiber length.

\section{TEST PROgRAM FOR FIBER ORIENTATION FACTOR}

\section{A. Test Variables, Material Properties, and Test Procedure}

In order to investigate fiber orientation factor on rectangular concrete section, dog-bone fiber reinforced concrete specimens with rectangular cross-section of $70 \times 100$ $\mathrm{mm}$ or $50 \times 50 \mathrm{~mm}$ were prepared as illustrated in Fig. 1 and 2 . Test variables were concrete compressive strength, fiber type, and concrete cross-section size. Notations for test variables are presented in Fig. 3, and the concrete mixture design and fiber details are presented in Table I and Table II, respectively.

TABLE I: FIBER REINFORCED CONCRETE MIX PROPORTION

\begin{tabular}{cccccccc}
\hline \hline & \multirow{2}{*}{ W/B } & W & C & SF & S & G & AD \\
\hline $\mathrm{N}$ & 0.35 & 200 & 572 & - & 798 & 627 & 1.43 \\
$\mathrm{H}$ & 0.25 & 200 & 737 & 64 & 667 & 569 & 6.01 \\
\hline \hline
\end{tabular}

TABLE II: PROPERTIES FOR END-HOOKED STEEL FIBERS

\begin{tabular}{ccccc}
\hline \hline $\begin{array}{c}\text { Fiber } \\
\text { type }\end{array}$ & $\begin{array}{c}\text { Length } \\
(\mathrm{mm})\end{array}$ & $\begin{array}{c}\text { Diameter } \\
(\mathrm{mm})\end{array}$ & $\begin{array}{c}\text { Tensile } \\
\text { strength }(\mathrm{MPa})\end{array}$ & $\begin{array}{c}\text { Aspect } \\
\text { Ratio }\end{array}$ \\
\hline$F_{1}$ & 50 & 1.05 & 1000 & 47.6 \\
$F_{2}$ & 35 & 0.55 & 1100 & 63.6 \\
$F_{3}$ & 30 & 0.38 & 2300 & 78.9 \\
\hline \hline
\end{tabular}

All specimens had been subjected to uniaxial tension until they were entirely separated due to a crack, then the number of fibers on crack surfaces were counted. From the number of fibers $\left(N_{f}\right)$, the fiber orientation factor can be evaluated from the cross-sectional area of fiber $\left(A_{f}\right)$, fiber volumetric ratio $\left(V_{f}\right)$, and cross-sectional area of concrete member $\left(A_{c}\right)$, as following equation [12], [13].

$$
\alpha_{f}=\left(N_{f} A_{f}\right) /\left(V_{f} A_{c}\right)
$$



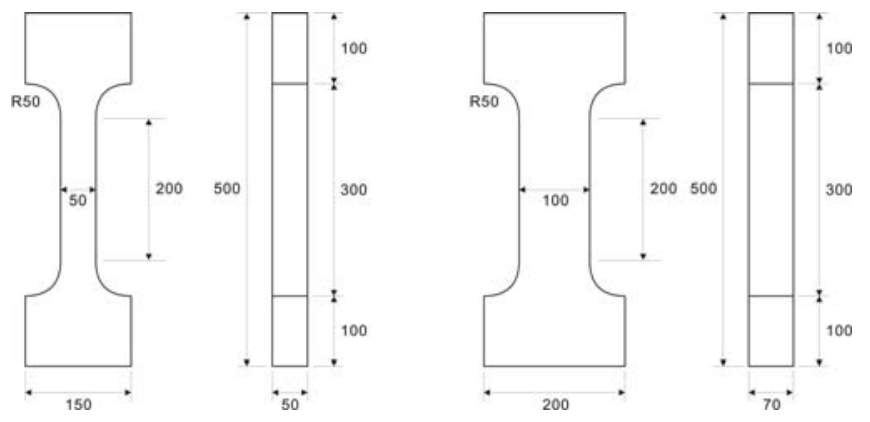

Fig. 1. Details of the specimens.
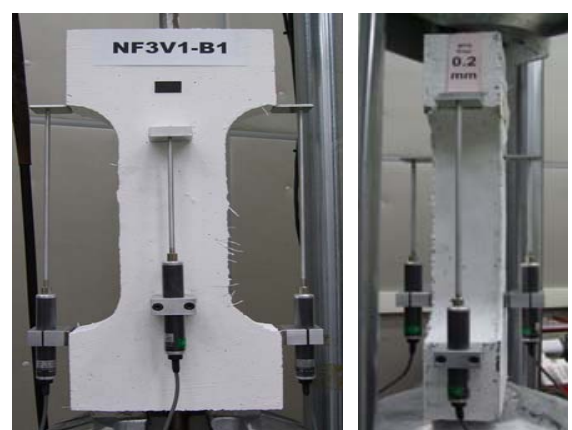

Fig. 2. Test set-up

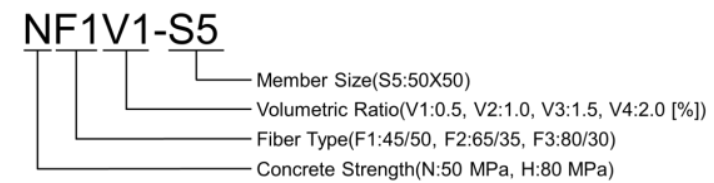

Fig. 3. Notations for the test variables.

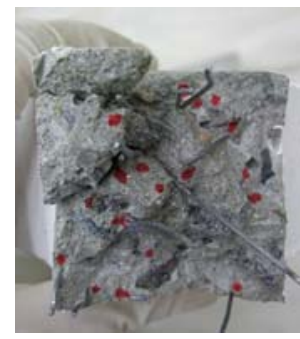

(a) NF1V3-S5

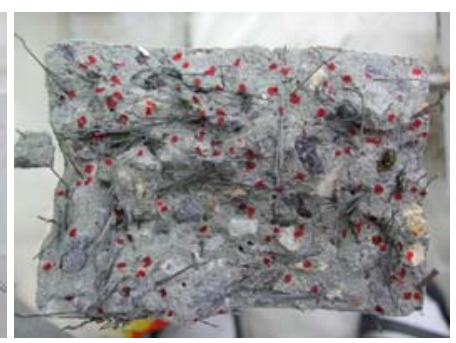

(b) NF3V3

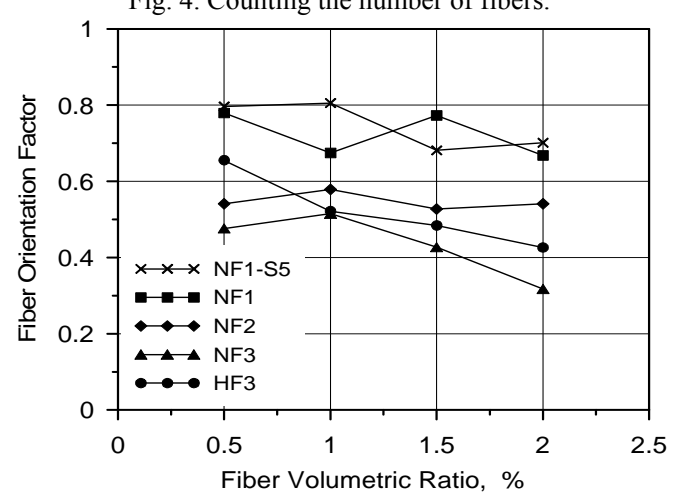

Fig. 5. Test results for fiber orientation factor.

\section{B. Test Results}

The fiber orientation factors observed through the number of fibers on a crack (see Fig. 4) are presented in Fig. 5 and Table III. It is noted that each point in the graph represents the fiber orientation factor averaged through four specimens. As presented in the figure, the fiber orientation factor with $\mathrm{F} 1$ on the small section was high because fiber distribution is significantly affected by the boundary surfaces of the rectangular cross-section. (Compare NF1 and NF1-S5.) In the case of NF3 and HF3 specimens, it was investigated that the fiber orientation factor generally decreases as the fiber volumetric ratio increases, since fibers were not evenly distributed because of fiber bundle easily found with small fibers.

TABLE III: MEASURED FIBER ORIENTATION FACTOR

\begin{tabular}{lccc}
\hline \hline Fiber type & $\begin{array}{c}\text { Fiber } \\
\text { volumetric ratio } \\
(\%)\end{array}$ & $\begin{array}{c}\text { Number of } \\
\text { fibers on a } \\
\text { crack }\end{array}$ & $\begin{array}{c}\text { Fiber } \\
\text { orientation } \\
\text { factor }\end{array}$ \\
\hline NF1V1-S5 & 0.5 & 12 & 0.797 \\
NF1V2-S5 & 1.0 & 23 & 0.805 \\
NF1V3-S5 & 1.5 & 30 & 0.681 \\
NF1V4-S5 & 2.0 & 41 & 0.701 \\
NF1V1 & 0.5 & 32 & 0.779 \\
NF1V2 & 1.0 & 55 & 0.674 \\
NF1V3 & 1.5 & 94 & 0.773 \\
NF1V4 & 2.0 & 108 & 0.668 \\
NF2V1 & 0.5 & 80 & 0.541 \\
NF2V2 & 1.0 & 171 & 0.579 \\
NF2V3 & 1.5 & 233 & 0.527 \\
NF2V4 & 2.0 & 319 & 0.541 \\
NF3V1 & 0.5 & 147 & 0.476 \\
NF3V2 & 1.0 & 318 & 0.515 \\
NF3V3 & 1.5 & 396 & 0.427 \\
NF3V4 & 2.0 & 392 & 0.318 \\
NF3V1 & 0.5 & 202 & 0.655 \\
NF3V2 & 1.0 & 322 & 0.522 \\
NF3V3 & 1.5 & 448 & 0.484 \\
NF3V4 & 2.0 & 526 & 0.426 \\
\hline \hline
\end{tabular}

\section{Simple MODEl FOR FiBER ORIENTATION FACTOR}

\section{A. Derivation of a Simple Model}

In the Diverse Embedment Model (DEM) [9], [10], the fiber orientation factor on rectangular concrete cross-section is evaluated through double numerical integration, so it is quite complicating. In this paper, through regression procedure to remove the double numerical integration, a simple fiber orientation factor has been derived as followings.

$$
\begin{gathered}
\alpha_{f}=-0.1\left(\left(\frac{h}{l_{f}}\right)^{2.8}+\left(\frac{b}{l_{f}}\right)^{2.8}\right)+1 \\
\text { for } \frac{h}{l_{f}} \leq 1.0, \frac{b}{l_{f}} \leq 1.0 \\
\alpha_{f}=-\frac{\left(0.05\left(b / l_{f}\right)^{2.8}\left(\left(h / l_{f}\right)^{1.12}+1\right)-0.26\right)}{\left(h / l_{f}\right)}+0.64 \\
\alpha_{f}=\frac{0.12}{\left(b h / l_{f}^{2}\right)^{1.12}}+0.087\left(\left(\frac{l_{f}}{b}\right)^{1.12}+\left(\frac{l_{f}}{h}\right)^{1.12}\right)+0.5 \\
\text { for } \frac{h}{l_{f}}>1.0, \frac{b}{l_{f}}>1.0
\end{gathered}
$$

In Fig. 6, the predictions of the simple fiber orientation factor model are compared with the results of the DEM. As 
presented in the figure, the both DEM and the proposed model predicts that the fiber orientation factor for infinite concrete cross-section is 0.5 , and it increases up to 1.0 . In addition, the fiber orientation factor increases more quickly when width or height of concrete cross-section is less than two times of the fiber length, since fiber orientation is significantly affected by more than one boundary surface together. As compared in the figure, it can be concluded that the simple fiber orientation factor model shows good agreement with the DEM.

\section{B. Verification of the Simple Model}

Fiber orientation factors for the test specimens have been evaluated with the proposed simple model, and compared with the test results as presented in Table IV and Fig. 7. As presented in the figure, the actual fiber orientation factors measured through the test program are well predicted by the proposed simple model; average and standard deviation are 0.938 and 0.197 , respectively, for the ratio of the test result to the prediction.

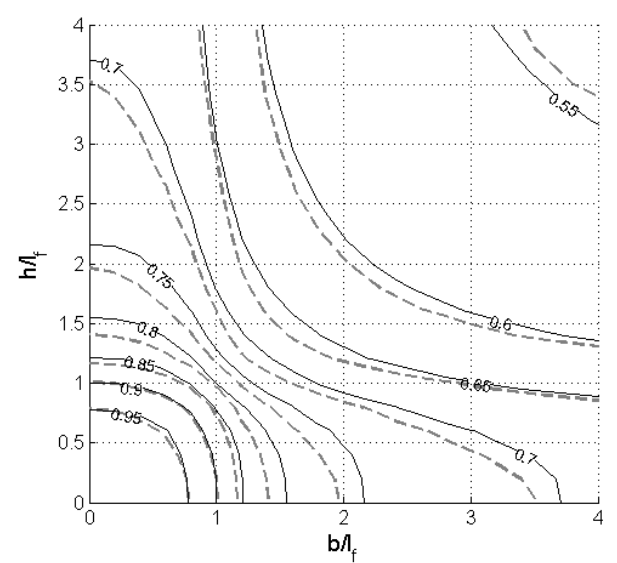

Fig. 6. Comparison of the simple model and the DEM.
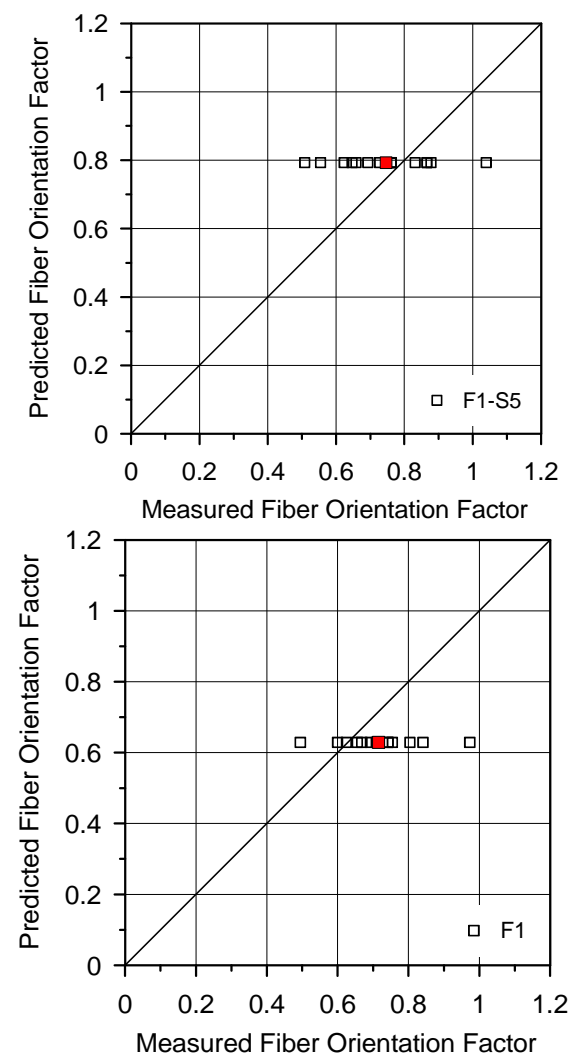
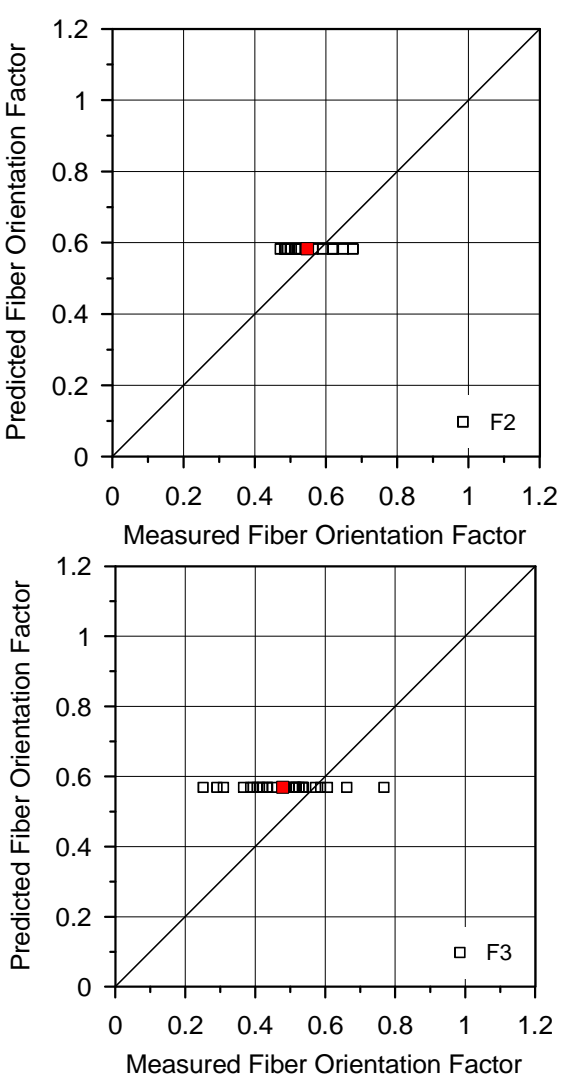

Fig. 7. Comparison of the prediction and the test results on fiber orientation factor.

TABLE IV: COMPARISON OF THE PREDICTION WITH THE TEST RESULTS ON FIBER ORIENTATION FACTOR

\begin{tabular}{|c|c|c|c|c|}
\hline \multirow{2}{*}{ Fiber type } & \multicolumn{2}{|c|}{ Fiber orientation factor } & \multirow{2}{*}{$\begin{array}{c}\text { Measured } \\
/ \\
\text { Prediction }\end{array}$} & \multirow{2}{*}{$\begin{array}{l}\text { Standard } \\
\text { deviation }\end{array}$} \\
\hline & Measured & Predicted & & \\
\hline F1-S5 & 0.746 & 0.793 & 0.941 & 0.174 \\
\hline F1 & 0.716 & 0.629 & 1.138 & 0.175 \\
\hline $\mathrm{F} 2$ & 0.547 & 0.583 & 0.939 & 0.108 \\
\hline F3 & 0.547 & 0.569 & 0.840 & 0.188 \\
\hline \multicolumn{3}{|c|}{ Total } & 0.938 & 0.197 \\
\hline
\end{tabular}

\section{CONCLUSIONS}

In this paper, fiber orientation factor on rectangular cross-section in concrete members were investigated through test program with dog-bone specimens. From the test results, it was investigated that fiber orientation factor was significantly affected by the concrete member cross-section size and the fiber length; fiber orientation factor increases as the cross-section size-to-fiber length ratio decreases. In order to predict fiber orientation factor considering the size effect, a simple model has been derived. The predictions of the proposed simple model showed good agreement with the test results as well as the predictions of the previous rigorous model. The results presented in this paper can be useful for researches on structural behavior of concrete members and structures with steel fibers.

\section{REFERENCES}

[1] G. J. P. Montesinos, "High-performance fiber-reinforced cement composites: an alternative for seismic design of structures," $A C I$ Structural Journal, 2005, vol. 102, no. 5, pp. 668-675.

[2] F. Minelli and F. J. Vecchio, "Compression field modeling of fiber-reinforced concrete members under shear loading," $A C I$ Structural Journal, 2006, vol. 103, no. 2, pp. 244-252. 
[3] H. H. Dinh, G. J. P, Montesinos, and J. K. Wight, "Shear behavior of steel fiber-reinforced concrete beams without stirrup reinforcement," ACI Structural Journal, 2010, vol. 107, no. 5, pp. 597-606.

[4] J. Susetyo, P. Gauvreau, and F. J. Vecchio, "Effectiveness of steel fiber as minimum shear reinforcement," ACI Structural Journal, 2011, vol. 108 , no. 4, pp. 488-496.

[5] P. Marti, T. Pfyl, V. Sigrist, and T. Ulaga, "Harmonized test procedures for steel fiber-reinforced concrete," ACI Structural Journal, 1999, vol 96, no. 6, pp. 676-686.

[6] J. Y. L. Voo and S. J. Foster, "Variable engagement model for fibre reinforced concrete in tension," Uniciv Report No. R-420, School of Civil and Environmental Engineering, the University of New South Wales, 2003.

[7] T. Leutbecher and E. Fehling, "Crack width control for combined reinforced of rebars and fibers exemplified by ultra-high-performance concrete," Fib Task Group 8.6. Ultra High Performance Fiber Reinforced Concrete - UHPFRC, 2008, pp. 1-28.

[8] P. Stroeven, "Stereological principles of spatial modeling applied to steel fiber-reinforced concrete in tension," ACI Materials Journal, 2009, vol. 106, no. 3, pp. 213-222.

[9] S. C. Lee, J.-Y. Cho, and F. J. Vecchio, "Diverse embedment model for fiber-reinforced concrete in tension: model development," $A C I$ Materials Journal, 2011, vol. 108, no. 5, pp. 516-525.

[10] S.-C. Lee, J.-Y. Cho, and F. J. Vecchio, "Diverse embedment model for fiber-reinforced concrete in tension: model verification," $A C I$ Materials Journal, 2011, vol. 108, no. 5, pp. 526-535.

[11] S.-C. Lee, J.-Y. Cho, and F. J. Vecchio, "Simplified diverse embedment model for steel fiber-reinforced concrete elements in tension," ACI Materials Journal, 2013, vol. 110, no. 4, pp. 403-412.

[12] J. Aveston and A. Kelly, "Theory of multiple fracture of fibrous composites," Journal of Materials and Science, 1973, vol. 8, pp. 352-362.
[13] P. Soroushian and C.-D. Lee, "Distribution and orientation of fibers in steel fiber reinforced concrete," ACI Materials Journal, 1990, vol. 87, no. 5 , pp. 433-439.

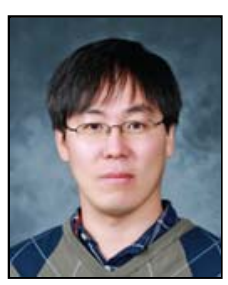

Seong-Cheol Lee is an assistant professor at KEPCO International Nuclear Graduate School (KINGS) in South Korea. He received his $\mathrm{PhD}$ from Seoul National University, Seoul, Korea, in 2007, and then he was a post-doctoral researcher in the Department of Civil Engineering at the University of Toronto, Toronto, $\mathrm{ON}$, Canada. His research interests include the shear behavior of concrete structures and the analysis of prestressed concrete structures and fiber-reinforced

concrete members.

Jeong-Hwan Oh is a staff member at the Office of Offshore Windpower Promotion, KETEP, Seoul in South Korea. He received his master degree from Seoul National University, of which the subject is structural modeling of steel fiber reinforced concrete.

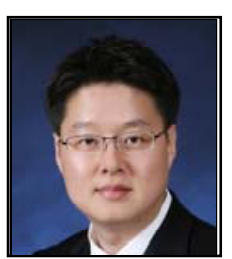

Jae-Yeol Cho is an associate professor in the Department of Civil \& Environmental Engineering at Seoul National University. He received his $\mathrm{PhD}$ from Seoul National University. His research interests include nonlinear analysis and optimized design of reinforced and prestressed concrete structures, material modeling, and similitude laws for dynamic test of concrete structures. 